\title{
Land degradation assessment for sustainable soil management
}

\author{
Francesca Assennato, Marco Di Leginio, Marco d'Antona, Ines Marinosci, Luca Congedo, \\ Nicola Riitano, Anna Luise, Michele Munafò \\ Italian Institute for Environmental Protection and Research (ISPRA), Rome, Italy
}

\begin{abstract}
Desertification is a complex phenomenon defined as the extreme degree of land degradation induced by human activities and climatic conditions. Climate change is accelerating and widening these areas.

Previews analysis and studies assessed the vulnerability to desertification in Italy at national and regional level through a methodological approach based on integrating climate, soil, vegetation, and socio-economic data (ESA). The studies carried out by ISPRA aim to provide an update of the of land degradation assessment in Italy, based on Trends.Earth methodology and of the three UN-SDGs sub-indicators on Target 15.3.1 (land use/land cover, land productivity and soil organic carbon above and below ground status and trends), together with additional dimensions of land degradation considered crucial for national land characters. Final assessment of the percentage of degraded land is around $36 \%$ of national area. This exercise demonstrates the importance to consider a larger number of data and include information on other factors, such as climate, physical, chemical data. This integrated approach to the assessment of land degradation will allow to describe also of the loss of related ecosystem services.
\end{abstract}

\section{Introduction}

Land is a complex system of soil, water and biodiversity interactions providing services on which sustainable livelihoods are based. However, land is a non-renewable resource, and the land degradation processes threaten the health, livelihoods and safety of many people. Land degradation is defined as a negative trend

Correspondence: Francesca Assennato, Italian Institute for Environmental Protection and Research (ISPRA), via Vitaliano Brancati 48, 00144 Rome, Italy.

E-mail: francesca.assennato@isprambiente.it

Key words: Land degradation; land consumption; soil functions; ecosystem services; productivity.

Received for publication: 2 November 2020.

Accepted for publication: 11 November 2020.

CC Copyright: the Author(s), 2020

Licensee PAGEPress, Italy

Italian Journal of Agronomy 2020; 15:1770

doi:10.4081/ija.2020.1770

This article is distributed under the terms of the Creative Commons Attribution Noncommercial License (by-nc 4.0) which permits any noncommercial use, distribution, and reproduction in any medium, provided the original author(s) and source are credited. in land condition, caused by direct or indirect human-induced processes including anthropogenic climate change, expressed as long-term reduction or loss of at least one of the following: biological productivity, ecological integrity, or value to humans (Olsson et al., 2019). The $3^{\text {rd }}$ World Atlas of Desertification (Cherlet et al., 2018) uses a wider definition: land degradation leads to a long-term failure to balance demand for and supply of ecosystem goods and services, i.e. direct and indirect benefits to people from ecosystems depending upon specific soil properties and functions (MEA, 2005; Dominati et al., 2010) covering desertification issues, but also problems linked to droughts and floods, to encroachment of urban areas and overexploitation of soils.

The complexity of this phenomenon represents a challenge for the scientific community either to develop a unique methodology or to harmonize the already existing methodologies, in order to adopt appropriate as well as comparable methods to assess and monitor land vulnerability and land degradation processes (Symeonakis et al., 2016; Pravalie et al., 2017, 2020; Giuliani et al., 2020a).

In this context, the conservation of ecosystem functions and services, while also supporting human wellbeing, are the primary goals of sustainable land management (SLM). SLM has in fact a strong relevance to the United Nations Environmental Conventions (UNFCCC, UNCCD and UNCBD), as well as to the UN Agenda 2030 and related Sustainable Development Goals (SDGs) (Helming et al, 2018), particularly SDG 15 on protecting land-based ecosystems and biodiversity but also many others related to food production, water, etc. (Ministry for the Environment, Land and Sea, 2017).

Related Target 15.3 calls for By 2030, combat desertification, restore degraded land and soil, including land affected by desertification, drought and floods, and strive to achieve a land degradation-neutral world, introducing the concept of land degradation neutrality (LDN).

The UNCCD, the only binding legislative framework on desertification and land degradation, defines LDN as a state whereby the amount and quality of land resources necessary to support ecosystem functions and services and enhance food security remain stable or increase within specified temporal and spatial scales and ecosystems (UNCCD, 2015) [Parties of the UNCCD recognize that within the scope of the Convention, this definition is intended to apply to affected areas as defined in the text of the Convention.]. Among all of the six progress indicators adopted by the same Conference of Parties [Decision 22/COP.11], three land-based indicators (namely land cover and land cover change, land productivity status and carbon stock value and changes) and associated metrics allow to estimate progress towards achieving LDN. These indicators, already monitored in the context of the UNCCD reporting process (UNCCD, 2017 and 2018), in line with the SDG indicator 15.3.1 (Proportion of land that is degraded over total land area) established by UN Statistical Commission.

The indicator 15.3.1 is reported as a binary (i.e., degraded/not degraded) quantification, based primarily on the assessment of the 
three above mentioned sub-indicators: i) land cover, as vegetation cover to assess land conversion trends and the possible loss of ecosystem services; ii) land productivity, to determine changes in health and capacity of primary production; iii) soil organic carbon trends, to quantify overall soil quality.

In particular, the UN Good Practice Guidance for SDG Indicator 15.3.1 recommends assessing their value utilising comparable and standardized national official data sources. The UNCCD recommends (but does not prescribe) that the set of three above mentioned indicators should be complemented by other relevant national (or sub-national) indicators (Wunder and Bodle, 2019). This could help to obtain an even more accurate picture of the current status of land and the progresses made towards LDN (Global Mechanism of the UNCCD, 2016; IAEG-SDGs, 2016).

Italy is the only developed country engaged in the pilot assessment program launce by UNCCD and then one of the more than 120 countries voluntary committed to setting LDN targets in the framework of the UNCCD wider LDN Target Setting Program. Data on LDN were utilised in last national UNCCD report delivered in August 2018 (Chasek et al., 2019). A previous assessment referred to land degradation processes, based on vegetation land cover and climatic data (Salvati and Baiocco, 2011) showed an increasing pressure on land; most vulnerable areas to environmental degradation was mainly detected in the southern-central part of Italy, where climate characteristics associated to human activity pressure were supposed to contribute to land degradation processes (Salvati et al., 2014).

Recent studies and analysis utilised told us that negative impact on land is mainly driven by land cover change (Munafò, 2018, 2019). They are based on the set of the three sub-indicators, in line with the international approach adopted by UNCCD for LDN and for SDGs 15.3.1 indicator Proportion of degraded land on total land. These indicators were integrated with other sub-indicators to better address specific conditions at national level, such as habitat fragmentation and quality of soils and ecosystems, linked to ecosystems services provision. The aim of the paper is to discuss the relevance of this approach to assess the main causes of land degradation giving a qualitative framework with the numbers of negative factors affecting different areas.

\section{Materials and methods}

Italy is located in central-southern Europe, the characteristic shape of the peninsula extends into the Mediterranean Sea, originating a coastal development of about $8300 \mathrm{~km}$. Two large mountain ranges dominate the landscape: the Alps, in the northern part of the peninsula, among the most rugged in the world, and the Apennine, which forms the backbone of the continental part of the country. While the Alps surround the Po river basin, a large plain, the Apennines leave room for coastal plains facing the Tyrrhenian and Adriatic Sea. Two major islands (Sardinia and Sicily) and nearly 800 smaller islands complete the territory. These characteristics, added to the geomorphological, microclimatic and vegetational peculiarities, make Italy a country with a strong landscape diversification, shaped over the centuries by anthropic pressures, historically conditioned by unique cultural and social factors and by urbanization dynamics in the recent past.

The methodology adopted in this study is based on the UNCCD recommendations (UNCCD, 2017). It considers the addition of other relevant national (or sub-national) indicators to land cover, land productivity and carbon stocks indicators. Particularly the following indicators were additionally calculated: loss of habitat quality, burnt areas, fragmentation index, density of artificial surfaces and buffer areas, and Increasing of small natural patches, from now on referred to as sub-indicators.

The study used two reference years, 2012 and 2018, and utilised Trends.Earth model (Gonzalez-Roglich et al., 2019), developed by FAO with the guidance of UNCCD (http://trends. earth/docs/en/). It is a free and open source tool supported by a cloud-based system available as a QGIS plugin. It can separately generate the three sub-indicators and combine them to calculate indicator 15.3.1. Useful tools in the package are the data collecting, preparation and results visualization integrated in a minimal graphic interface (Meyer and Riechert, 2019) and usage of the Google Earth Engine to process data (Gorelick et al., 2017).

Elaboration process data for 2012 and 2018 is illustrated below. The final result follows the One Out, All Out approach: if one of the sub-indicators is negative (or stable when degraded in the baseline or previous monitoring year) in a specific land unit, it would then be considered as degraded, subject to ground validation by national authorities (UNCCD, 2017).

\section{Land cover}

UNCCD suggests considering land cover data with 300 meters of resolution produced by European Spatial Agency (ESA) as part of the Climate Change Initiative. Although, the method approached at national level considers land consumption map produced by SNPA with 10 meters of spatial resolution integrated by Corine Land Cover dataset for cropland, natural and forest areas and wetland (CLC, 2012, 2018). According to IPPC legend, the input raster based in the standard CLC nomenclature including 44 land cover classes, have been reclassified in six groups: cropland, forestland, grassland, settlement, wetlands and other lands. All possible transitions are shown in Figure 1.

\section{Productivity}

Land productivity can be measured across large areas utilising Earth observations data on net primary productivity (NPP). NPP is the net amount of carbon assimilated after photosynthesis and autotrophic respiration over a given period of time (Clark et al., 2001) and is typically represented in units such as $\mathrm{kg} / \mathrm{ha} / \mathrm{year}$ (annual NPP or ANPP). Remote sensing techniques are the most effective way to measure ANPP in fine detail at national scales, but Earth observation sensors do not directly measure it. One of the most commonly used surrogates of primary productivity is the normalized difference vegetation index (NDVI), which is an indicator of green leaf productivity and biomass (Tucker, 1979).

Trends.Earth toolbox currently supports AVHRR $(8 \mathrm{~km})$ and MODIS $(250 \mathrm{~m})$ data for primary productivity analysis.

The assessment of land productivity considers three metrics: trend (e.g., rate of change in primary production over time), state (e.g., detection of changes in primary productivity as compared to a baseline period) and performance (e.g., local productivity relative to other areas that share a similar land cover type over the dedicated region) (UNCCD, 2017; Sims et al., 2019).

The trend (or trajectory) is calculated through linear regression in each pixel to identify positive or negative correlation across the considered time series (MODIS series from 2001 to 2018 with 1 $\mathrm{km}$ of spatial resolution).

The measure of state results from the comparison of the annual integrals of NDVI for each pixel in recent years with the historical 
observation (baseline period) of NDVI in the same area. We assessed the index matching the baseline period (on MODIS images 2001-2012) with the recent monitoring period (20122018). The value of two periods have been divided into classes, from the smallest to the largest (1-10) considering the following possibilities: NDVI (monitoring period) - NDVI (baseline) $<-2$ : potential degraded areas, if $-1<\mathrm{NDVI}$ (monitoring period) NDVI (baseline) $<1$ : stable areas and if NDVI (monitoring period) - NDVI (baseline) $>2$ : improved areas.

Finally, productivity performance is calculated by comparing the average NDVI value with the productivity of ecologically similar areas (the model uses the intersection of land cover - 37 ESA $\mathrm{CCI}$ at $300 \mathrm{~m}$ resolution - and SoilGrid USDA at $250 \mathrm{~m}$ resolution).

\section{Soil organic carbon}

The third sub-indicator can be generated using satellite EO data even if the assessment is difficult due to spatial variability of soils, lack of consistent time-series data and standardized soil organic carbon (SOC) information system, etc. (Stumpf et al., 2018; Angelopoulou et al., 2019). On the other hand, conventional methods for SOC monitoring are expensive and time consuming. The methodology proposed by Trends.Earth use a combination of land cover and SOC changes (Giuliani et al., 2020b). This approach suggested to determine SOC using Italy's assessment contained in Global Soil Organic Carbon Map produced in the Global Soil Partenrship framework (GSOCmap - FAO and ITPS, 2018). The aforementioned assessment considers data from 6.748 soil profiles collected between 1990 and 2013 and spatialized through concepts and techniques of Digital Soil Mapping.

\section{Additional sub-indicators}

As stated before, more specific indicators were utilised in order to allow a more accurate description of land degradation for the period 2012-2018, as illustrated in Figure 2: i) Loss of habitat quality: assessed through InVEST model habitat quality; the model combines information on Land Use/Land Cover and threats to biodiversity and calculates several parameters based on spatial analysis (Assennato et al., 2018); ii) Burnt areas: fires database allowing the assessment of burnt areas during 2008-2018 provided by Carabinieri Command unit for the protection of forests, the environment and agri-food (CUFAA); the vector file of burnt area was converted to raster in order to compare the data with the other indicators; iii) Fragmentation Index (or increasing of mesh density): fragmentation from roads, railroads and urban settlements is represented through the mesh density (number of patches in a grid of $1000 \mathrm{~km}^{2}$ ). It is calculated according to the effective mesh size methodology (Jaeger, 2000) and modified according to the crossboundary connections procedure (Moser et al., 2007); the difference between the mesh density of 2018 and 2012 was calculated, resulting in degradation with a difference greater than 10 meshes/1000 km²; iv) Density of artificial land cover: urban and suburban areas, as defined in the target 11.7 of SDGs, are considered degraded areas; degradation occurs when the density of artificial cover increases in the target period (2012-2018); v) Density of buffer areas: the potential negative impact is calculated as 60 meters buffer around polygons in artificialized land class; the degradation is represented by the increase in potential impact area in the period 2012-2018; vi) Increasing of small natural patches $<1000 \mathrm{~m}^{2}$ : small natural patches are calculated through spatial analysis as patches of not consumed land with area less than 1000

\section{Land cover in target year}

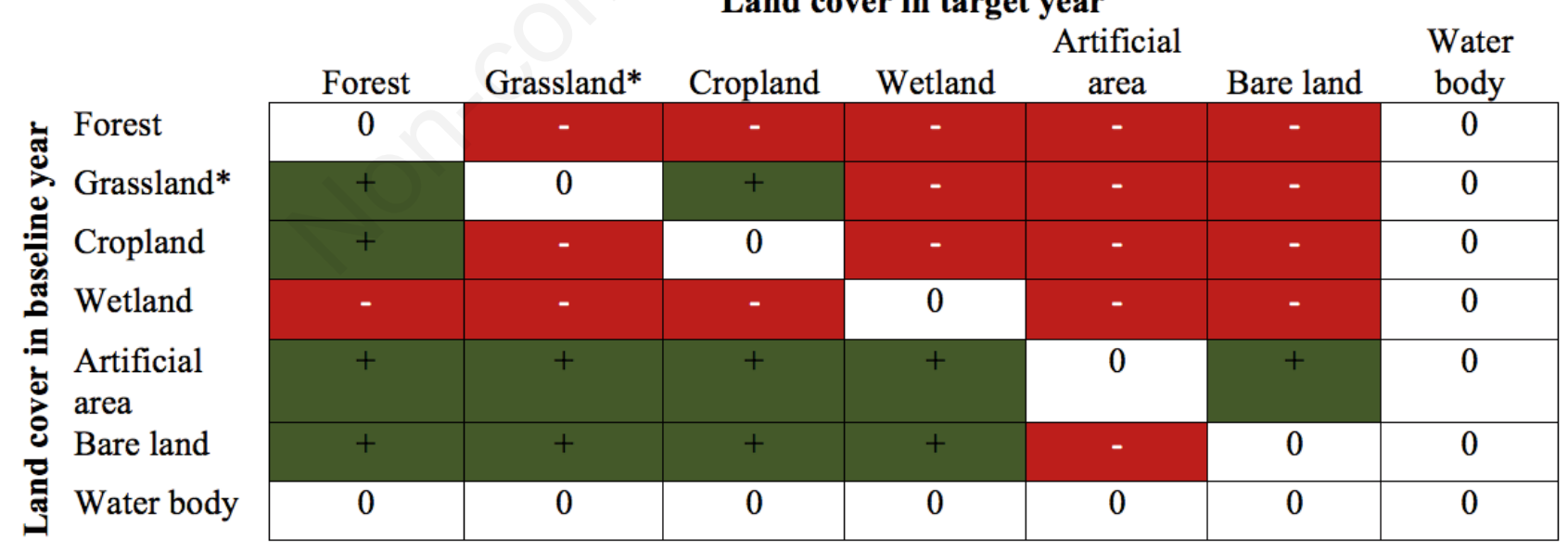

Legend

Degradation

Stable

Improvement

*the Grassland class consists of grassland, shrub and sparsely vegetated areas (if default aggregation is used).

Figure 1. Summary of the land cover/land use change for the IPCC classes (30 possible transitions); the colour highlights improvement (green), stable (light grey) or degradation (red). 
$\mathrm{m}^{2}$; the new patches created between 2012 and 2018 are considered as land degradation.

For each degradation cause described above, results are produced as raster layer with $20 \mathrm{~m}$ of spatial resolution. The spatial overlay of all layers allows to map total land degradation in Italy, and to calculate the number of degradation causes for each pixel, as well as to calculate the area of degradation for each sub indicator.

\section{Results and discussion}

The main result is the extension of land degradation in the 2012-2018 timeframe, assessed considering the different factors (Table 1) and pixel-based map over the entire country at a spatial resolution of $20 \mathrm{~m}$ (Figure 3), representing that degraded areas are concentrated mainly in fertile agricultural land and in correspondence of large urban areas.

Results showed the level of degradation in terms of number of causes thereof (1-2- $\geq 3$ ) (Table 2). Around $80.000 \mathrm{~km}^{2}$ (26.53\%) are subjected to an increasing degradation even if in many cases only one factor insists $(22.96 \%)$. The area of degradation by at least 3 causes, results in almost $800 \mathrm{~km}^{2}$, representing $0.26 \%$ of the national territory.

These results, compared with the official set of three sub-indicators by UNCCD, underline the prevalence of areas degraded by
Table 1. Degraded areas under different causes (2012-2018).

\begin{tabular}{lcc} 
Indicator & $\mathrm{km}^{2}$ & \% of IT territory \\
Land cover change & 1094 & 0.40 \\
Productivity & 9420 & 3.12 \\
\hline Organic carbon decline & 670 & 0.22 \\
Loss of habitat quality & 33,977 & 11.26 \\
\hline Burnt areas & 2374 & 0.8 \\
Fragmentation Index & 44,259 & 14.68 \\
\hline Areas of potential impact & 409 & 0.14 \\
Density of artificial land cover & 951 & 0.32 \\
\hline Increasing of not sealed areas & 14 & 0.005 \\
\hline
\end{tabular}

Table 2. Degraded areas for one or more causes (2012-2018).

\begin{tabular}{lcc} 
Number of causes & $\mathrm{km}^{2}$ & $\%$ of IT territory \\
1 & 69,323 & 22.96 \\
2 & 9961 & 3.30 \\
\hline$>3$ & 796 & 0.26 \\
Total & 80,079 & 26.53 \\
\hline
\end{tabular}

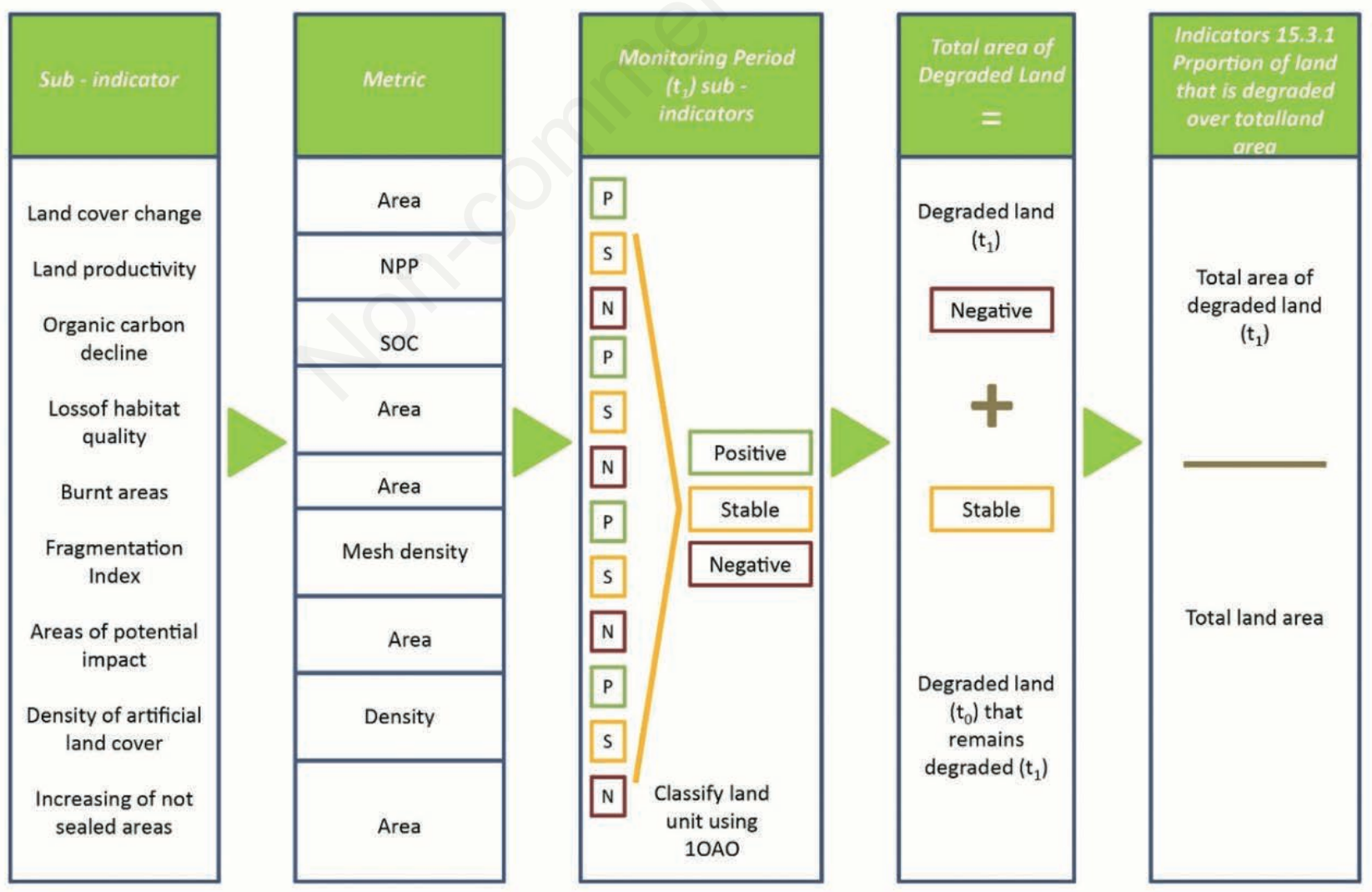

Figure 2. Steps to derive LD indicator for Italy (Adapted from UNCCD, 2017). 


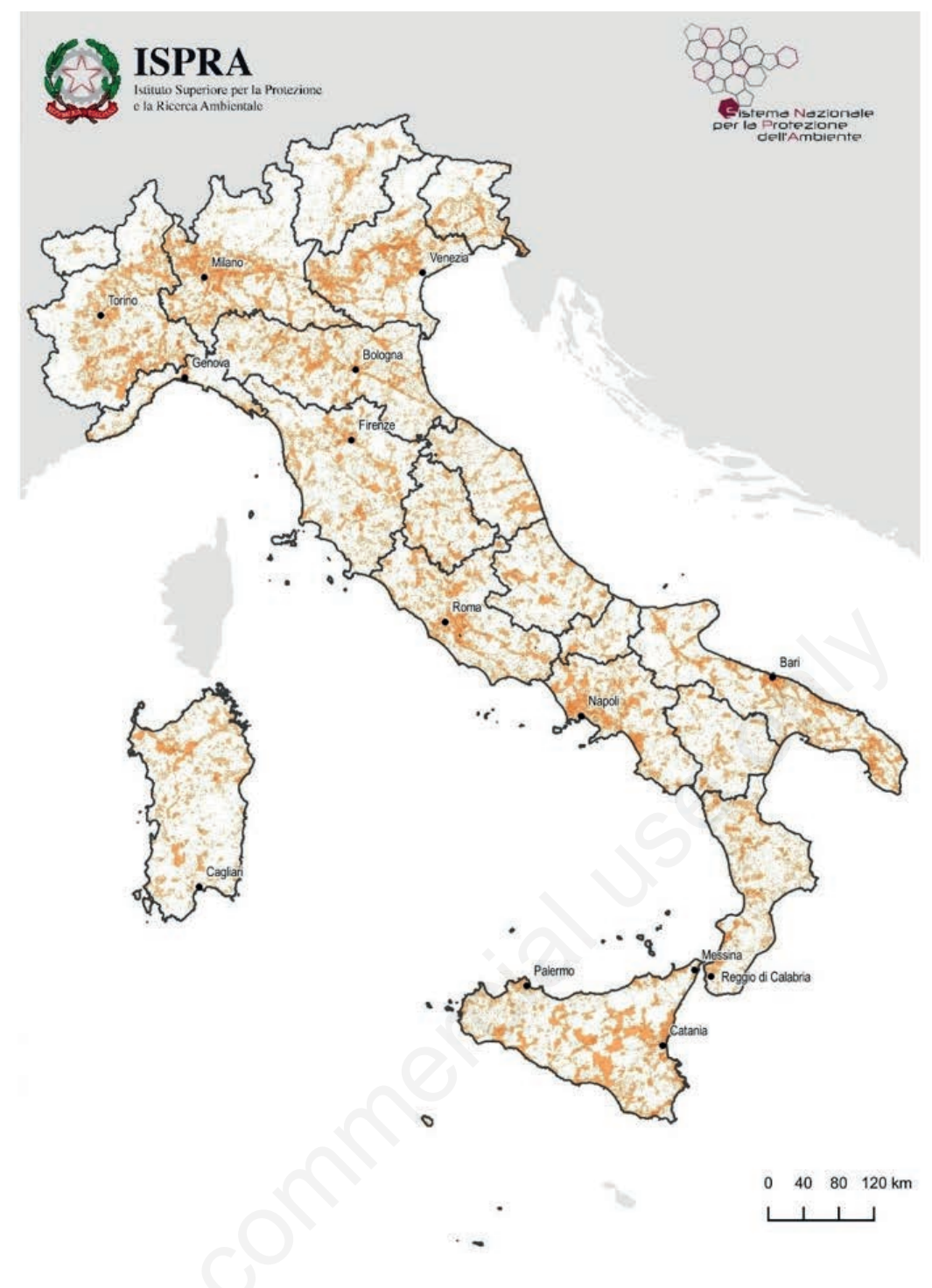

Figure 3. Map of degraded areas distribution (2012-2018).

fragmentation and loss of habitat, while the strict set of land cover, productivity and organic carbon cover a very limited national land surface. The percentage of degraded land is $26.53 \%$ according to our assessment, while the value calculated using the strict UNCCD approach, namely the three main sub indicators, is 3.54\%, varying from Valle d'Aosta region 1\% to Emilia Romagna more than $6 \%$.

It must be pointed out that the preliminary estimate from UNCCD Report from ITALY released in 2018 (https://prais.unccd. int/sites/default/files/pdf_reports/unccd_Italy_2018_1.pdf), was $13.4 \%$ for the $2000-2015$ period, being not directly comparable with our assessment because of different methodology and time frame.

This high variability, depending on indicators selected and detail of inputs, confirm the necessity of improved national indicators to enhance compliance with the official UN SDG reporting system, by taking into account parameters that are not yet currently considered as shown by previous studies (Giuliani et al., 2020a and 2020b). Additionally, the possibility to disaggregate indicators at high-resolution and capturing both spatial and temporal dynamics of land degradation will result in more effective support to decision-makers.

This assessment is a preliminary result, obtained by the overlay of sub-indicators mainly related to land cover changes. More accurate results could be available by improving data and sub-indicators in consideration of climate conditions (drought, rainfall, etc.), physical (compaction, water erosion) and chemical (salinization, contamination) degradation phenomena (Salvati et al., 2011). The monitoring of land degradation adopted for Italy will take into account such improvements, while the ecosystems state and level of services supply will be useful to better address degradation effects.

The proposed assessment highlights the opportunity to consider high resolution territorial information on the different causes of degradation, being the original three indicators less effective in capturing high diversity of landscapes and habitats in Italian territory. 


\section{Conclusions}

There is still the need for some technical improvement of LDN indicators to obtain an accurate land degradation picture, integrating also climate data as well as a better representation of physical and chemical phenomena. However, this study is a first attempt to account for the many causes of degradation, and it is the starting point towards a more complete assessment of LDN indicators.

The assessment provided for Italian territory reveal the urgency to stimulate the adoption of more sustainable land management measures in each land-use sector, especially in areas with a projected increasing pressure on land and water resources. The main challenge is to overcome the sectoral fragmentation between land use planning, agricultural production, forestry, protection of natural capital and landscape. The prevention of land degradation could be improved with a more complete approach to the assessment of land degradation and of soil ecosystem services, based on our capacity to better understand the ongoing phenomena and forecast their evolution.

A better, more accurate assessment would provide a strong base to consider alternative scenarios of future land challenges and to quantitatively describe how the deteriorating condition of land may influence ecosystem services and functions, creating a crucial base for sustainable land management tools and programs.

\section{Highlights}

- Assessment and mapping of land degradation in Italy, toward an improvement of SDG Target 15.3 indicator.

- Trends.Earth methodology integrated with additional data and information, in order to map ecosystem conditions and related ecosystem services provision.

- Focus on land cover change as Italy main degradation factor.

- Analysis with disaggregated results is provided for a deeper understanding of the specific contribution of the sub-indicators at the local level.

- Improving sustainable land management by integrating land degradation prevention.

\section{References}

Angelopoulou T, Tziolas N, Balafoutis A, Zalidis G, Bochtis D, 2019. Remote sensing techniques for soil organic carbon estimation: a review. Remote Sens. Basel 11:676.

Assennato F, Braca G, Calzolari C, Capriolo A, di Leginio M, Giandon P, Marchetti M, Marino D, Mascolo R, Morri E, Pettenella D, Pileri P, Sallustio S, Salvati L, Santolini R, Soraci M, Strollo A, Terribile F, Ungaro F, Vinci I, Munafò M, 2018. Mappatura e valutazione dell'impatto del consumo di suolo sui servizi ecosistemici: proposte metodologiche per il Rapporto sul consumo di suolo. Annex. In: M. Munafò (Ed.), Soil consumption, territorial dynamics and ecosystem services; 2018 Edition. Report 288/2018. Available from: http://www.isprambiente.gov.it/files2018/pubblicazioni/rapporti/copy_of_Annes sometodologicoalRapportoServiziecosistemici_2018.pdf

Chasek P, Akhtar-Schuster M, Joseph Orr B, Luise A, Rakoto Ratsimba H, Safriel U, 2019. Land degradation neutrality: The science-policy interface from the UNCCD to national implementation. Env Sci Policy 92:182-90.

Cherlet M, Hutchinson C, Reynolds J, Hill J, Sommer S, von
Maltitz G (Eds.), 2018. World atlas of desertification. Publication Office of the European Union, Luxembourg.

Clark DA, Brown S, Kicklighter DW, Chambers JQ, Thomlinson JR, Jian Ni J, 2001. Measuring net primary production in forests: concepts and field methods. Ecol. Appl. 11:356-70.

Dominati E, Patterson M, Mackay A, 2010. A framework for classifying and quantifying the natural capital and ecosystem services of soils. Ecol. Econ. 69:1858-68.

FAO, ITPS, 2018. Global soil organic carbon map. Available from: http://54.229.242.119/GSOCmap/

Giuliani G, Chatenoux B, Benvenuti A, Lacroix P, Santoro M, Mazzetti P, 2020a. Monitoring land degradation at national level using satellite Earth Observation time-series data to support SDG15 - exploring the potential of data cube. Big Earth Data 4:3-22.

Giuliani G, Mazzetti P, Santoro M, Nativi S, Bemmelen JV, Colangeli G, Lehmann A, 2020b. Knowledge generation using satellite earth observations to support sustainable development goals (SDG): a use case on land degradation. Int. J. Appl. Earth Obs. 88.

Global Mechanism of the UNCCD, 2016. Achieving land degradation neutrality at the country level. Building blocks for LDN target setting. Available from: https:/www.unccd.int/publications/achieving-land-degradation-neutrality-country-levelbuilding-blocks-ldn-target-setting.

Gonzalez-Roglich M, Zvoleff A, Noon M, Liniger H, Fleiner R, Harari N, Garcia C, 2019. Synergizing global tools to monitor progress towards land degradation neutrality: Trends.Earth and the World Overview of Conservation Approaches and Technologies sustainable land management database. Env. Sci. Policy 93:34-42.

IAEG-SDGs, 2016. IAEG-SDGs - SDG Indicators. Sustainable development goals. Available from: http:/unstats.un.org/ sdgs/iaeg-sdgs/metadata-compilation/int/sites/default/files/relevant-links/2017-10/Good\%20Practice\%20Guidance

Jaeger JAG, 2000. Landscape division, splitting index, and effective mesh size: New measures of landscape fragmentation. Landscape Ecol. 15:115-30.

Helming K, Daedlow K, Hansjürgens B, Koellner T, 2018. Assessment and governance of sustainable soil management. Sustainability-Basel 10:4432.

MEA, Millennium Ecosystem Assessment, 2005. Ecosystems and human well-being: wetlands and water synthesis. World Resources Institute, Washington, DC, USA.

Meyer D, Riechert M, 2019. Open source QGIS toolkit for the advanced research WRF modelling system. Environ. Model. Softw. 112:166-78.

Ministry for the Environment, Land and Sea, 2017. National Sustainable Development Strategy 2017/2030, Rome, Italy.

Moser B, Jaeger JAG, Tasser E, Eiselt B, Tappeiner U, 2007. Modification of the effective mesh size for measuring landscape fragmentation to solve the boundary problem. Landscape Ecol. 22:447-59.

Munafò M (Ed.), 2018. Soil consumption, territorial dynamics and ecosystem services - 2018 edition. Report ISPRA 288/2018.

Munafò M (Ed.), 2019. Soil consumption, territorial dynamics and ecosystem services - 2019 edition. Report SNPA 08/19.

Olsson L, Barbosa H, Bhadwal S, Cowie A, Delusca K, FloresRenteria D, Hermans K, Jobbagy E, Kurz W, Li D,Sonwa D.J, Stringer L, 2019. Land degradation. In: P.R. Shukla, J. Skea, E. Calvo Buendia, V. Masson-Delmotte, H.-O. Pörtner, D. C. Roberts, P. Zhai, R. Slade, S. Connors, R. van Diemen, M. Ferrat, E. Haughey, S. Luz, S. Neogi, M. Pathak, J. Petzold, J. 
Portugal Pereira, P. Vyas, E. Huntley, K. Kissick, M. Belkacemi, J. Malley, (eds.). Climate Change and Land: an IPCC special report on climate change, desertification, land degradation, sustainable land management, food security, and greenhouse gas fluxes in terrestrial ecosystems. [In press].

Pravalie R, Patriche C, Bandoc G, 2017. Quantification of land degradation sensitivity areas in Southern and Central Southeastern Europe. New results based on improving DISMED methodology with new climate data. Catena 158:309-20.

Pravalie R, Patriche C, Savulescu I, Sîrodoev I, Bandoc G, Sfîca L, 2020. Spatial assessment of land sensitivity to degradation across Romania. A quantitative approach based on the modified MEDALUS methodology. Catena 187.

Salvati L, Bajocco S, 2011. Land sensitivity to desertification across Italy: past, present, and future. Appl. Geogr. 31:223-31.

Salvati L, Bajocco S, Ceccarelli T, Zitti M, Perini L, 2011. Towards a process-based evaluation of land vulnerability to soil degradation in Italy. Ecol. Indic. 11:1216-27.

Salvati L, Smiraglia D, Bajocco S, Tomaso Ceccarelli T, Zitti M, Perini L, 2014. Map of long-term changes in land sensitivity to degradation of Italy. J. Maps 10:65-72.

Sims NC, England JR, Newnham GJ, Alexander S, Green C, Minelli S, Held A, 2019. Developing good practice guidance for estimating land degradation in the context of the United Nations Sustainable Development Goals. Env. Sci. Policy 92:349-55.

Stumpf F, Keller A, Schmidt K, Mayr A, Gubler A, Schaepman M, 2018. Spatio-temporal land use dynamics and soil organic carbon in swiss agroecosystems. Agric. Ecosyst. Environ. 258:129-42.

Symeonakis E, Karathanasis N, Koukoulas S, Panagopoulos G,
2016. Monitoring sensitivity to land degradation and desertification with the environmentally sensitive area index: the case of Lesvos island. Land Degrad Dev 27:1562-73.

Tucker CJ, 1979. Red and photographic infrared linear combinations for monitoring vegetation. Remote Sens. Environ. 8:12750.

UNCCD, 2015. Report of the Conference of the Parties on its twelfth session, held in Ankara from 12 to 23 October 2015. Part two: Actions taken by the Conference of the Parties at its twelfth session. ICCD/ COP(12)/20/Add. Bonn: United Nations Convention to Combat Desertification. Available from: https://www2.unccd.int/sites/default/files/sessions/documents/ICCD_COP12_20_Add.1/20add1eng.pdf

UNCCD, 2016. Achieving Land Degradation Neutrality at the Country Level: Building Blocks for LDN Target Setting. UNCCD, Bonn. Available from: https://www.unccd.int/publications/achieving-land-degradation-neutrality-country-levelbuilding-blocks-ldn-target-setting

UNCCD, 2017. 'Good Practice Guidance. SDG Indicator 15.3.1 Proportion of Land That Is Degraded Over Total Land Area. Version 1.0 September 2017'. Available from: http://www2.unced.int/sites/default/files/relevant-links/201710/Good\%20Practice\%20Guidance_SDG\%20Indicator\%2015 .3.1_Version\%201.0.pdf

UNCCD, 2018. 'The LDN Target Setting Programme. Website of the United Nations Convention to Combat Desertification (UNCCD)'. Available from: https://www.unced.int/actions /ldn-target-setting-programme

Wunder S, Bodle R, 2019. Achieving land degradation neutrality in Germany: Implementation process and design of a land use change based indicator. Env. Sci. Policy 92:46-55. 